San Jose State University

SJSU ScholarWorks

Master's Theses

Master's Theses and Graduate Research

1989

\title{
A Study to assess the health promotion behaviors and health training needs of child care center teachers and child care home providers
}

Anna Lu

San Jose State University

Follow this and additional works at: https://scholarworks.sjsu.edu/etd_theses

\section{Recommended Citation}

Lu, Anna, "A Study to assess the health promotion behaviors and health training needs of child care center teachers and child care home providers" (1989). Master's Theses. 3088.

DOI: https://doi.org/10.31979/etd.ckg9-dxev

https://scholarworks.sjsu.edu/etd_theses/3088

This Thesis is brought to you for free and open access by the Master's Theses and Graduate Research at SJSU ScholarWorks. It has been accepted for inclusion in Master's Theses by an authorized administrator of SJSU ScholarWorks. For more information, please contact scholarworks@sjsu.edu. 


\section{INFORMATION TO USERS}

The most advanced technology has been used to photograph and reproduce this manuscript from the microfilm master. UMI films the text directly from the original or copy submitted. Thus, some thesis and dissertation copies are in typewriter face, while others may be from any type of computer printer.

The quality of this reproduction is dependent upon the quality of the copy submitted. Broken or indistinct print, colored or poor quality illustrations and photographs, print bleedthrough, substandard margins, and improper alignment can adversely affect reproduction.

In the unlikely event that the author did not send UMI a complete manuscript and there are missing pages, these will be noted. Also, if unauthorized copyright material had to be removed, a note will indicate the deletion.

Oversize materials (e.g., maps, drawings, charts) are reproduced by sectioning the original, beginning at the upper left-hand corner and continuing from left to right in equal sections with small overlaps. Each original is also photographed in one exposure and is included in reduced form at the back of the book. These are also available as one exposure on a standard $35 \mathrm{~mm}$ slide or as a $17^{\prime \prime} \times 23^{\prime \prime}$ black and white photographic print for an additional charge.

Photographs included in the original manuscript have been reproduced xerographically in this copy. Higher quality $6^{\prime \prime} \times 9^{\prime \prime}$ black and white photographic prints are available for any photographs or illustrations appearing in this copy for an additional charge. Contact UMI directly to order.

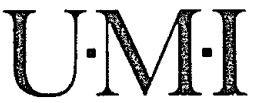


Order Number 1337822

\begin{abstract}
A study to assess the health promotion behaviors and health training needs of child care center teachers and child care home providers
\end{abstract}

Lu, Anna, M.S.

San Jose State University, 1989

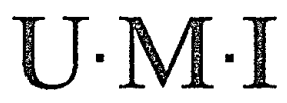

300 N. Zecb Rd.

Ann Arbor, MI 48106 



\begin{abstract}
A STUDY TO ASSESS THE
HEALTH PROMOTION BEHAVIORS AND HEALTH TRAINING NEEDS

$\mathrm{OF}$ CHILD CARE CENTER TEACHERS AND CHILD CARE HOME PROVIDERS
\end{abstract}

\author{
A Thesis \\ Presented to \\ The Faculty of the Department of Nursing \\ San Jose State University \\ In Partial Fulfillment \\ of the Requirements for the Degree \\ Master of Science
}

By

Anna Lu

Maly 1989 
APPROVED FOR THE DEPARTMENT OF NURSING

Shaver Hogan
Sharon Hogan, RN, MS

Nigel Passover

Virgil Parsons, RN, DNSc.

Sherman Ware

Sharon Wall, RN, MS

APPROVED FOR THE UNIVERSITY

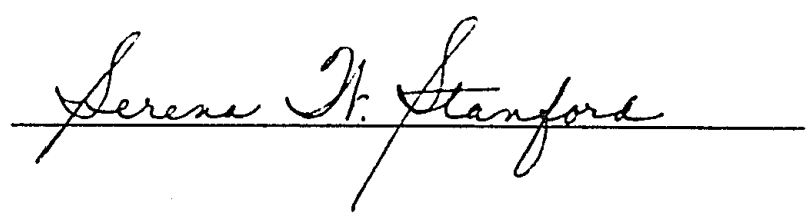

ii 
TO:

My dear baby daughter

\section{Ting Yuan}




\section{ACKNOWLEDGEMENTS}

It is a great pleasure to acknowledge the many people who have assisted me in the development and completion of this thesis.

I am deeply indebted to the following people for helping me over numerous questions and for reviewing and criticizing of the draft of the questionnaire: Sharon Hogan, Judy Blanding, and Monica Brivolich.

I would also like to thank Caroline Swanson, the supervisor of Neighborhood Day Care Program, and Barbara Rieder, the director of Public Health Nursing, for permission to use the questionnaire in their programs and workshops.

In addition, to Sharon Hogan, Virgil Parsons, and Sharon Wahl, my thanks for the guidance and patience they have shown through the production of this thesis.

Finally, special appreciation goes to my parents and my husband, Felix Yuan, for supporting me financially and spiritually to get my degree. 


\begin{abstract}
A STUDY TO ASSESS THE HEALTH PROMOTION BEHAVIORS AND HEALTH TRAINING NEEDS OF CHILD CARE CENTER TEACHERS AND CHILD CARE HOME PROVIDERS.
\end{abstract}

\title{
By Anna Lu
}

This study was done to determine whether 12 units of required early childhood education credit for child care center teachers made a difference in their health promotion behaviors when compared with child care home providers who do not have this requirement. Four health promotion behaviors in the areas of nutrition, sleep/rest, physical awareness, and sanitation were explored. In addition, the health training needs for both of these groups were assessed. A closed-ended structured questionnaire was mailed to child care home providers and distributed at two workshops to child care center teachers. A total of 21 center teachers and 18 home providers participated.

Two of the four health promotion behaviors reached significance at the .05 level using the chi square statistic. These results indicate that the 12 units of early childhood education made little difference in the center teachers' health promotion behaviors. 
TABLE OF CONTENTS

Page

LIST OF TABLES $\ldots \ldots \ldots \ldots \ldots \ldots \ldots \ldots \ldots \ldots \ldots \ldots$ viii

LIST OF FIGURE $\ldots \ldots \ldots \ldots \ldots \ldots \ldots \ldots \ldots \ldots \ldots$

Chapter

1. INTRODUCTION. .................. 1

Problem Statement. . . . . . . . . . . . . . . . . . 2

Purpose and Need..................... 3

Research Questions.................. 3

Definitions....................... 3

Sample and Setting. .................. 4

Research Design.................... 4

Scope and Limitations................... 5

2. CONCEPTUAL FRAMEWORK AND LITERATURE REVIEW. . 6

Conceptual Framework ................. 6

Literature Review................... 10

3. METHOD. .................... 17

Research Design. .................... 17

Data Collection Tool .................. 17

Data Collection Procedure. ................ 18

Data Analysis ........................ 19

4. DATA ANALYSIS AND INTERPRETATION......... 20

Analysis of Personal Information Data ........... 20

Analysis of Health Promotion Behaviors Data . . . . . . . . 29 
Analysis of Health Training Needs Data . . . . . . . . 45

5. CONCLUSIONS AND RECOMMENDATIONS. ....... 50

Conclusions. ................... 50

Limitations. . . . . . . . . . . . . . . 52

Recommendations. ................ 53

REFERENCES. ..................... 55

APPENDICES

A. Cover Letter . . . . . . . . . . . . . . . . . 59

B. Consent Form ..................... 61

C. Questionnaire ........................ 64

D. Permission Letter from Santa Clara County Health Department

Director of Nursing. . . . . . . . . . . 70

E. Permission Letter from the Supervisor of Neighborhood Day

Care Program. . . . . . . . . . . . . . 72

F. Approval Form from Human Subjects Institutional Review

Board, San Jose State University. . . . . . . . . . . 74 


\section{LIST OF TABLES}

Tables

1. Thinking Capabilities During the Preoperational Period

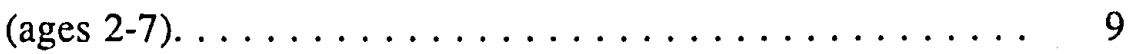

2. Daily Food Plan and Serving Portions. . . . . . . . . . . 12

3. A Table to Evaluate Each Child's Immunization Status . . . . . 14

4. Age Distribution of Center Teachers and Home Providers by Number and Percentage of People. . . . . . . . . . . . 21

5. Formal Education of Center Teachers and Home Providers by Number and Percentage of People. . . . . . . . . . .

6. Early Childhood Education Units of Center Teachers and Home Providers by Number and Percentage of People. . . . . . . .

7. Health Education Related to Child Care Taken by Center Teachers and Home Providers by Number and Percentage of People. . . 25

8. First Aid Training of Center Teachers and Home Providers by Number and Percentage of People. . . . . . . . . . .

9. Frequency of Reading Child Care Magazines/Books of Center Teachers and Home Providers by Number and Percentage of People. . . . . . . . . . . . . . . . . . 28

10. Chi Square Test for Balanced Diet by Center Teachers' and Home Providers' Answers. . . . . . . . . . . . . 30

11. Chi Square Test of Sleep/Rest Requirements for Toddlers (Age 1-3) from Center Teachers' and Home Providers' Answers. . . . . . . . . . . . . . 
12. Chi Square Test for Sleep/Rest Requirements for Preschoolers (Age 4-6) from Center Teachers' and Home Providers' Answers. . . . . . . . . . . . . . . .

13. Chi Square Test of Follow Up Immunization Record for Children from Center Teachers' and Home Providers' Answers. . . . . . . . . . . . . . . . . .

14. Chi Square Test of Dental Care for Children from Center Teachers' and Home Providers' Answers. . . . . . . . . .

15. Chi Square Test of Disinfectant Solution from Center Teachers' and Home Providers' Answers. . . . . . . . . . .

16. Chi Square Test of Disinfected Surfaces from Center Teachers' and Home Providers' Answers. . . . . . . . . . . . 40

17. Frequency Data for Disinfection of Surfaces from Center Teachers' and Home Providers' Answers by Number of People ..... .

18. Chi Square Test of Handwashing from Center Teachers' and Home Providers' Answers. . . . . . . . . . . . . . . .

19. Enough First Aid Training from Center Teachers' and Home Providers' Answers by Number and Percentage of People . .

20. Areas of First Aid Training Needs of Center Teachers and Home Providers by Number and Percentage of People. . . . . . .

21. Topics of Health Education Needs of Center Teachers and Home Providers by Number and Percentage of People. ....... 


\section{LIST OF FIGURE}

Figure Page

1. Pender's Health Promotion Model. . . . . . . . . . . . . 7 


\section{Chapter 1}

\section{INTRODUCTION}

A significant change in the American family has resulted in a greater demand for child care. With the dramatic increase in single-parent households and nuclear families in which both parents work, America has entered the age of child care.

In 1984, over two-thirds of American women worked outside their homes compared with about one-half in 1975 (Rowan \& Mazie, 1985). As women go to work, the need for child care grows and the age of children who need child care becomes younger and younger. According to data from the U.S. Bureau of Census (1982), almost $25 \%$ of the preschoolers in the United States receive out-of-home care by nonrelatives, as compared to $9 \%$ in 1958. In 1977, $38 \%$ of the children under 6 years of age had w/orking mothers, and it is projected that $45 \%$ will have working mothers by the year 1990 (U.S. Department of Health and Human Services, 1981).

Obviously, the demand for child care services is inevitable in the American society. In the future, even more children will take their first step under a child care provider other than their parents (Rowan \& Mazie, 1985). The position of the child care provider becomes increasingly important. The quality of health promotion and education in the child care setting is important and must be addressed. When children spend large amounts of time in a child care setting, it is necessary that the providers promote the well being of the children. These providers are caring for the next generation who will be in the mainstream of tomorrow's world.

Basically, there are two types of child care facilities in America. One is the child care home in which a few children are cared for by a woman in her own home. The other type of facility is the child care center, which provides care for a large number of children (Alston, 1984). Both of the settings service children from different families. In child care 
settings, there is physical interaction among children as well as interaction witl: child care providers. This interaction includes touching, sharing and handling of objects, and sharing space (Blanding, 1987). It is important that a child care provider has proper health promotion behaviors in order to protect children from illness and promote their health as much as possible.

\section{Problem Statement}

Children in child care facilities are at higher risk of infectious diseases than are those in their own homes (Blanding, 1987; Fleming, Cochi, Hightower, \& Broome, 1987). Also, the curiosity of boys and girls leads them into hazardous situations. Accidents are a leading cause of death among infants and small children. Therefore, prevention of diseases and accidents are important aspects in the care of children (Marlow, 1978). When the child care providers have health promotion behaviors and health training, they are better able to protect the children from death, illness, and permanent handicaps (Marlow, 1978).

However, according to California Title 22 Licensing Regulation, no health training is required of either the teachers of child care centers (Title 22, Chap. 2,1985) or child care home providers (Title 22, Chap. 3, 1985). Furthermore, no early child care education is required of child care home providers (Title 22, Chap. 3, 1985). But, 12 post-secondary semester units in early childhood education or child development are required of child care center teachers.

No studies can be found in the literature which compare and evaluate health promotion behaviors between child care center teachers and child care home providers as a result of the different educational requirements. The literature has minimally addressed the providers' need for health training. In addition, no statistical data could be found to indicate whether or not a lack of health promotion behaviors and health training are a problem for the child care center teachers and home providers. This study was designed to 
gather data on health promotion behaviors and health training needs of child care center teachers and child care home providers.

Purpose and Need

The purpose of this study was to identify the different health promotion behaviors practiced by child care center teachers and child care home providers. This study was also done to ascertain whether there is a difference in health promotion behaviors practiced by child care home providers with no educational requirements and child care center teachers who have mandated educational requirements.

The results of this study could be used to influence legislators, policy makers, and health professionals in their decisions regarding educational preparation of child care personnel. This study also assessed the participants' expressed needs for additional training programs which could be implemented at a later date to enhance the quality of child care.

\section{Research Questions}

This study answered the following questions:

1. Is there a difference in health promotion behaviors between child care center teachers, who have at least 12 post-secondary semester units of early childhood education or child development, and child care home providers who are not required to have this education?

2. What are the additional health training needs of child care center teachers and child care home providers?

\section{Definitions}

For the purpose of this study, the following definitions apply:

1. Young children are persons who are between the ages of $1-6$ years old. 
2. A child care center teacher is a person who has a children's center permit issued by the California Commission on Teacher Preparation and Licensing (Title 22, Chap. 2, 1985).

3. A child care home provider is a person who has received a written authorization by the State Department of Social Services or licensing agency to operate a family day care home (Title 22, Chap. 3, 1985).

4. Child care provider is a general term for persons who qualify for either a child care home provider or a child care center teacher.

5. Health promotion behaviors are all activities performed by child care providers which maintain or improve young children's physical or emotional well being, such as proper nutrition, disease prevention, play, rest, sleep, and sanitation.

\section{Sample and Setting}

All the child care home providers and child care center teachers who attended workshops conducted by a public health nurse in a metropolitan city were asked to participate. In addition, child care home providers who are members of a day care program were also invited to participate in this study. The public health nurse is an infant and child care health consultant. She conducts workshops to educate the child care providers in this city. The day care program is operated by the county department of social services in this community. The goal of this program is to provide quality child care in home settings for low-income families and those on social welfare.

\section{Research Design}

This study used a descriptive, non-experimental design. Child care center teachers and child care home providers were the participants. Because of the limited information on this topic, there were no available instruments to be used. A closed-ended structured questionnaire was designed as a tool to collect the data. A cover letter (Appendix A), a 
consent form (Appendix B), and the questionnaire (Appendix C) were distributed or mailed to the subjects. The Public Health Nursing Director granted permission to administer the questionnaire in the workshops conducted by a public health nurse (Appendix D). The supervisor of a day care program also gave permission to mail the questionnaire to their child care home providers (Appendix E). Approval was given from the Human Subjects Institutional Review Board at San Jose State University (Appendix F).

The questionnaire was designed to include health promotion behaviors which protect children and enhance their growth (for example, nutrition, sleep and rest, immunizations, dental health, and sanitation). In addition, the questionnaire requested that participants identify additional health training needs. A checklist was provided for each question.

All of the data received from the subjects were analyzed using the chi-square statistical test in order to determine whether or not a significant difference in health promotion behaviors existed between child care center teachers and child care home providers. Also, the demographic data were analyzed to determine whether or not there was any correlation with the health promotion behaviors and health training needs.

Scope and Limitations

This study was limited because the sample consisted of those child care providers who attended specific workshops and those who were contacted by mail. It did not represent all child care providers in this geographical area. Also, the questionnaire was written in English. The results of this study did not include those providers who could not read English. As a result, this study provided only a direction for the further studies. 
Chapter 2

\section{CONCEPTUAL FRAMEWORK AND LITERATURE REVIEW}

\section{Conceptual Framework}

The conceptual framework for this study includes two main concepts: (a) health promotion and (b) child development. Each concept will be discussed as it relates to the behaviors of child care providers which promote the growth and development of young children.

\section{Health Promotion}

Leavell and Clark state that health promotion is the first phase of primary prevention (Taylor, Ureda, \& Denham, 1982). In the process of evolution, the concept of health has been shifted from a biomedical definition and model of health and disease toward a broader, biopsychosocial view which involves the social and physical environment, as well as individual life style and behavior (Dychtwald, 1986). In a model proposed by Green, health promotion is a combination of health education and related organizational and politico-economic interventions designed to facilitate behavioral and environmental adaptations that will improve or protect health (Taylor et al., 1982). Pender (1982) also proposed a model for health promution (see Figure 1). This model is divided into two phases, the jecision making phase and the action phase. Movement of individuals back and forth between these two phases describes more accurately the health promotion process. Health promotion behaviors are those activities intended to enhance the health status of the individual. A person acts on his/her environment as s/he moves towards higher levels of health rather than reacting to external influences or threats posed by the environment. There are several determinants of health promotion behaviors which are individual perceptions of the importance of health, perceived control, and perceived health status (Christiansen, 1981). 


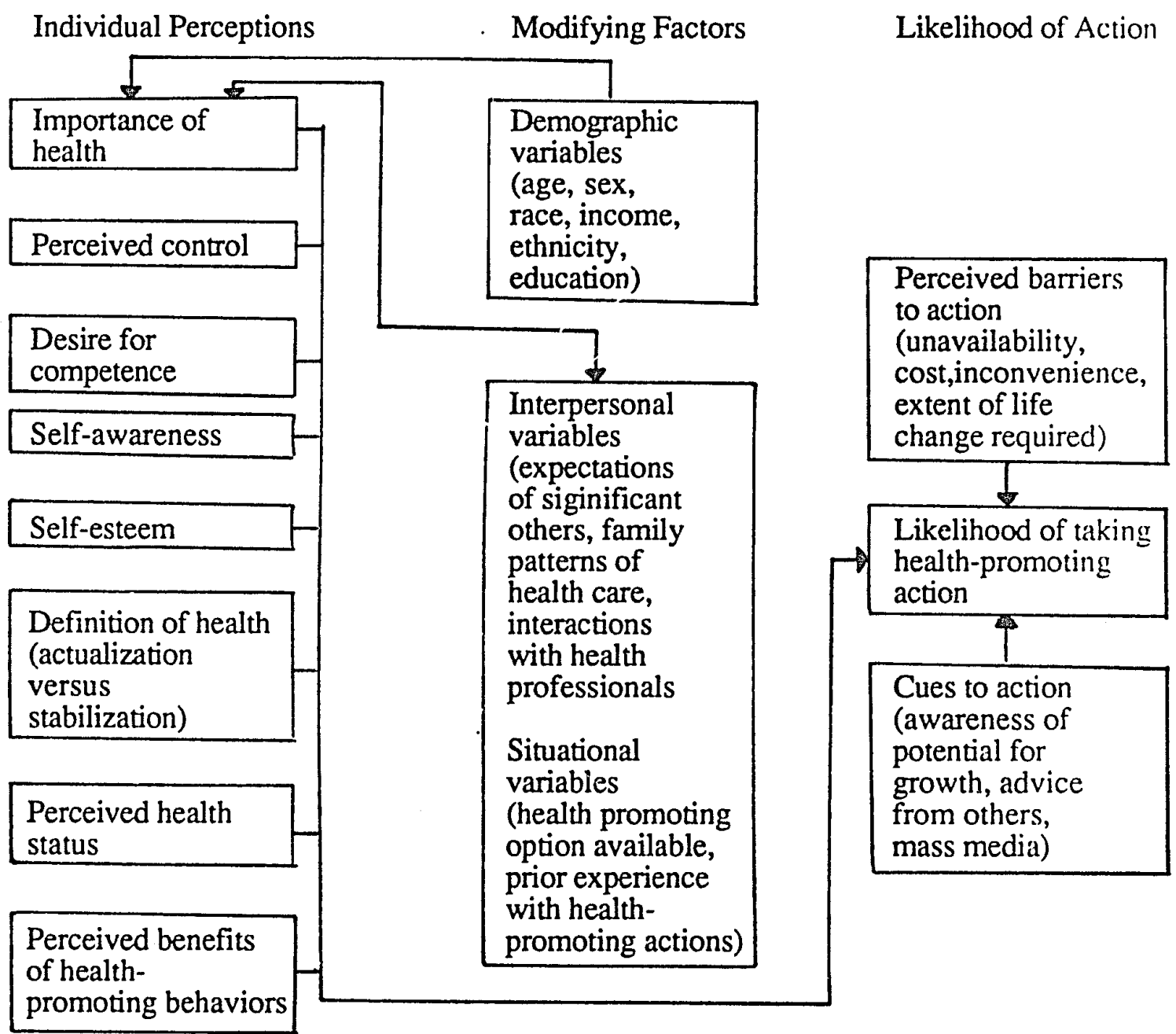

DECISION-MAKING PHASE

ACTION PHASE

Figure 1. Pender's health promotion model, from Pender, N. J. (1982). Health promotion in nursing practice. Prentice-Hall, East Norwalk, CT. 


\section{Child Development}

Child development is a term used to describe the biopsychosocial growth that occurs in all children from birth to adolescence. Only early childhood is addressed in this study. Early childhood includes children from ages 1 to 3 years (toddlers), and those from ages 3 to 5 years (preschoolers) (Dennis \& Hassol, 1983). Characteristics of early childhood will be discussed.

According to Erikson's emotional developmental theory, toddlers (ages 1 to 3 years) start to develop a degree of self-control. They learn to be self-sufficient in many activities, including toileting, feeding, walking, and talking. At the same time, they become more verbal and independent. Also, they may begin to challenge the care givers' suggestions by saying "NO." Erikson states that this kind of behavior is developing a will of autonomy. When children enter the preschool years, they want to learn self-care and be independent. In addition, they want to undertake many adult-like activities. They are developing initiative. However, sometimes they overstep the limits set by parents, and they will feel guilty (Harris, 1986; Marlow, 1978).

Another developmentalist theorist is Piaget. Piaget's developmental theory shows that children from ages 2 to 7 are in the preoperational stage. Children in this stage shape their world according to their own interests, and they do not shape their behaviors according to the demands of reality. They believe they are the center of the universe, and they feel that they can alter reality by their thoughts or wishes (Harris, 1986; Marlow, 1978).

Piaget futher describes the characteristics of children during the preoperational period with the concepts of symbolic thought, egocentrism, centration, animism, concreteness, and transductive reasoning. Each of these characteristics is described in Table 1. This table summarizes the thinking capabilities of children in Piaget's preoperational period. 
Table 1

Thinking Capabilities During the Preoperational Period (ages 2-7)

Characteristic

Description

Symbolic thought

The ability to use language to represent ideas and actions

Egocentrism

The belief that everything happens to, for, or because of the child

Centration

The tendency to focus on only one aspect of a problem or one point of view, ignoring all others

Animism

The tendency to attribute life to inanimate objects

Concreteness

The tendency to focus on things that are real, tangible, and measurable and observable

Transductive

The tendency to generalize from one specific event to another reasoning and to assume two events are causally related because they occur together in time

Note. From Child Development (p. 248) by A. C. Harris, 1986, St. Paul: West Publishing Company. 


\section{Summary}

Young children are unable at this age to perform health promotion behaviors by themselves. The child care provider can be a health provider and a health educator. They can help children to perform and develop health promotion behaviors. While teaching young children, a child care provider should be aware of the unique thinking capabilities of young children. For example, young children only focus on things that are real and observable. When a child care provider teaches the children the importance of washing hands and brushing teeth, it is better to use colored paper to represent a germ, and let the children see a germ (the colored paper) cleaned by using water. Also, young children focus on only one aspect of a problem or one point of view at a time. A simple and direct sentence will be more acceptable and effective with the children. Thus, by incorporating health promotion concepts with the developmental level of the child, more effective care can be provided by the child care providers, and health promotion behaviors can become a part of the child's normal behaviors.

\section{Literature Review}

Health promotion for young children is important to their normal development. The major areas of health promotion include: (a) nutrition, (b) play, (c) sleep and rest, (d) physical awareness, (e) sanitation, and (f) safety promotion. Because the young child is incapable of meeting these needs, the provider (parent or child care provider) must promote the child's health. Each of the health promotion areas will be discussed in this literature review as it relates to how the provider promotes the health of young children (ages 1 to 6 years).

\section{Nutritional Requirements}

Nutrition is important in the maintenance of young children's health, normal growth, and development. Children over age 1 need less food than infants, because they are no 
longer growing so rapidly. They are also developing an increased interest in their social and physical environment. Many children will even change their eating habits to a midmorning, midafternoon, and an evening snack due to their high level of activity. With this increase in activity also comes the problems of the "picky" eater. The children become finicky about what they eat. One of the most common complaints verbalized by parents of this age group is their frustration with the "picky eater" (Dennis \& Hassol, 1983).

The daily nutritional needs for young children are illustrated in Table 2. Child-care providers must know and provide for the nutritional needs of young children as they grow.

\section{Play, Sleep, and Rest Requirements}

Play is the business of childhood. Children grow, learn, develop, and mature through play. Giving children an opportunity to play creatively permits them to grow to their maximum creative potential (Marlow, 1978). But, rest is also as essential as play. After exploring and exerting boundless energy, children will reach the point of fatigue. Therefore, play and rest should be alternately arranged for the young children.

Normally, toddlers need an average of 10 to 12 hours of sleep at night and a daytime nap. Toddlers may have a toy in bed with them, but a variety of toys tend to keep them awake. Three-year-old children do not always need daytime naps, but will rest or play quietly for 1 or 2 hours if undisturbed. Four-year-old children resist daytime naps, but do need a quiet period, and five-year-old children do not take daytime naps if they get enough sleep at night (Murray \& Zentner, 1985). However, no study has been found to indicate how many hours of daytime nap or rest in a child care setting is proper for young children. 
Table 2

Daily Food Plan and Serving Portions

Pattern 1 to 3 years 3 to 6 years

Breakfast

milk

juice or fruit

cereal

bread

$1 / 2$ cup

$1 / 4$ cup

$1 / 4$ cup

$3 / 4$ cup

$1 / 2$ cup

$1 / 2$ slice

$1 / 3$ cup

$1 / 2$ slice

Mid-morning/Mid-afternoon

Supplement

Milk,Juice,Fruit,or

Vegetable

Bread

$1 / 2$ cup

$1 / 2$ slice

Cereal

$1 / 4$ cup

$1 / 2$ cup

$1 / 2$ slice

$1 / 3$ cup

Lunch/Supper

\begin{tabular}{|c|c|c|c|}
\hline Milk & & $1 / 2$ cup & $3 / 4$ cup \\
\hline Meat ( & one of the following or com & nations to give equivalent quantities) & \\
\hline & meat,poultry, or fish & 1 ounce & $11 / 2$ ounce \\
\hline & cheese & 1 ounce & $11 / 2$ ounce \\
\hline & egg & 1 & \\
\hline & cooked dry beans and peas & $1 / 8$ cup & $1 / 4$ cup \\
\hline & peanut butter & 1 tablespoon & 2 tablespoons \\
\hline Vegetab & ble and/or Fruit & $1 / 4$ cup & $1 / 2$ cup \\
\hline Bread & & $1 / 2$ slice & $1 / 2$ slice \\
\hline Butter o & or Fortified Margarine & $1 / 2$ teaspoon & $1 / 2$ teaspoon \\
\hline
\end{tabular}

Note. From Health of the Preschool Child (p. 35) by E. H. Reinisch and R. E. Minear, 1978, New York: John Wiley \& Sons. 


\section{Physical Awareness}

Physical awareness includes immunization and dental care. Immunization is a method of protection from diseases for young children. Children in the child care facility are at risk for morbidity associated with several types of acute illness. Haskins and Kotch's (1986) study showed that children in child care have higher rates of diarrhea, hepatitis A, meningitis, and possible otitis media than those not in child care. Young children's immunologic systems are not fully developed which puts them more at risk to contract diseases. Proper immunization can reduce morbidity for young children in the child care setting. Table 3 illustrates the immunization recommendations from the Centers for Disease Control (1985). The child care provider should ascertain whether the children under their care are fully immunized and encourage parents of non-immunized children to get them protection.

Dental care is also important for young children. Caries of the deciduous teeth commonly begin between the ages of three and six and tend to spread rapidly. Good dental hygiene habits can reduce the probability of caries. Therefore, helping the children to brush their teeth should be started as soon as possible, even a 2-year-old child can brush his/her own teeth. The teeth should be brushed after eating, and the children's intake of refined sugar should be limited (Pringle \& Ramsey, 1982). A study shows that "better education of parents in the proper care of their infants' and toddlers' teeth could contribute to a reduction in caries in the preschool age group" (Noravath, Douse, \& Skinner, 1986, p. 63). Because women are entering the work force by both choice and necessity, young children will spend more time with the child care provider than their own parent(s). Therefore, the child care provider with a proper knowledge and attitude of dental care is very important to the establishment of dental health behaviors of the young children. 
Table 3

A Table to Evaluate Each Child's Immunization Status

Age at Evaluation

Total Vaccine Doses

Required by This Age

Younger than 2 Months

none

2-3 months

Polio(OPV)

DPT/DT

1 dose

1 dose

4-5 months

Polio(OPV)

DPT/DT

2 doses

2 doses

6-14 months . . . . . . . . . . Polio(OPV)

DPT/DT

2 doses

3 doses

15-17 months

Polio(OPV)

DPT/DT

measles,

mumps,

rubella(MMR)

18 months through 4 years

Polio(OPV)

DPT/DT

measles,

mumps,

rubella(MMR)

2 doses

3 doses

1 dose

given on or

after first

birthday *

3 doses

4 doses

1 dose

given on or

after first

birthday *

* MMR is recommended at age 15 months

** Not legally required but recommended for some children: Haemophilus influenzae type $\mathrm{b}(\mathrm{Hib})$ vaccine

Note. From "What You Can Do to Stop Disease in Child Care Centers" by Centers for Disease Control, 1985. 


\section{$\underline{\text { Sanitation }}$}

Children like to climb and explore their world through their mouths. The expansion of social contacts in a child care setting exposes children to communicable diseases. In a study by Fleming, Cochi, Hightower, and Broome (1987), it was estimated that $9 \%$ to $14 \%$ of all upper respiratory track infections and ear infections in children less than 5 years old may occur as a result of child-care attendance. Therefore, proper sanitation can reduce the spread of disease in child care settings. According to the information of the State of California Department of Health Services (1986), the best way to reduce disease is by proper handwashing. In a study conducted by the Centers for Disease Control (1985), it was found that the most effective sanitation activity is using soap and water to wash the surfaces at the child care facility and then to use a fresh bleach solution (1/4 cup bleach per gallon of water) to disinfect the surfaces. The surfaces which become contaminated by staff and children include, but are not limited to, faucet handles, toilet seats, floors, and doorknobs. Surfaces in the bathroom should be washed and disinfected more than once a day, if possible. Surfaces that infants and young toddlers are likely to touch should be washed every day. Floors, low shelves, and doorknobs should be washed and disinfected every week.

\section{$\underline{\text { Safety Promotion }}$}

Safety promotion is the major responsibility of the child care provider. A study suggested that age-appropriate safety education results in an increase in the child care provider's knowledge and an improvement in certain safety practices (Kelly, Sein, \& McCarthy, 1987). Accidents of all kinds are the major cause of death and disability among children (U.S. Department of Health and Human Services, 1981). Approximately $40 \%$ of all deaths among those 1-4 years old are caused by accidents. In approximate order of frequency of accidents, motor vehicle accidents are the major proportion of these accidents. 
The rest are such factors as burns, falls, drownings, and poisoning (Marlow, 1978; Murray \& Zentner, 1985). The child care provider is more likely to see burns and falls. Therefore, careful observation is necessary if accidents are to be prevented. Child care providers need to routinely check the environment, both inside and outside in the play area, for potenial dangers. The children should also be taught what is safe and unsafe for them to do until they are mature enough to use their own judgement (Pringle \& Ramsey, 1982).

\section{Summary}

Children in early childhood are developing self-control and increasing their interest in the outside world. Their bodies are not as immunologically mature, making them susceptible to diseases. The responsibilities of the child care provider are great. They must provide an environment that is safe and promotes the health of the children in their care. 


\section{Chapter 3}

\section{METHOD}

\section{Research Design}

This study used a descriptive, non-experimental design. A closed-ended structured questionnaire was designed to collect the data from child care center teachers and child care home providers in order to assess the health promotion behaviors and health training needs of both groups. The personal information, such as age and educational level, was also evaluated in relation to the health promotion behaviors and health training needs of the participants.

\section{Data Collection Tool}

Because most of the data were collected by mail, a four page questionnaire was printed on two sheets to lessen the bulk of the questionnaire. The content of the questionnaire included: (a) a one page personal information section, (b) 12 questions on health promotion behaviors, and (c) two questions on health training needs. Personal information consisted of age, formal education, early childhood education units, health education related to child care, first aid training workshops, and frequency of reading magazines/books related to child care. This personal information included variables which would affect the health promotion behaviors and health training needs of the providers.

The questions on the health promotion behaviors were developed from the literature review which covered nutrition, sleep and rest, immunization, dental health, and sanitation. The criteria on health promotion behaviors was also determined by the information gained from the literature review. A checklist was provided for the questions on the health training needs in order to determine the future needs of the child care providers.

Two health educators specializing in child care were consulted to determine the format and validity of the questionnaire. One of the health educators works as an infant and child 
care health consultant in a county health department. She is a public health nurse with a master's degree in public health nursing education. The other consultant works as a health educator in a community child development council in a large metropolitan area. The draft form of the questionnaire was also reviewed by two child care professionals and one child care provider in order to make the wording simple and clear enough to be understood.

\section{Data Collection Procedure}

While working on practicum requirements for the master's degree in March, 1987, the investigator had the opportunity to work in the child care field and become aware of the problem in this field. The idea of the thesis, which was going to be dealing with child care, was gradually formed at that time.

In August, 1987, the problem area of the thesis was decided. Before completing the thesis proposal in January, 1988, five child care institutions were contacted to ensure the feasibility of this study. During Febuary, 1988, the Director of Public Health Nursing granted permission to use the questionnaire in workshops lead by a health educator in the public health department (Appendix D). Also, the supervisor of a day care program provided the roster of their child care home providers to the author for mailing out the questionnaire (Appendix E). On March, 1988, the proposal was submitted to the Human Subject's Commitee at San Jose State University and approval for the study was granted (Appendix F).

Data collection was done during March and April, 1988. Sixty-nine questionnaires with cover letters and consent forms were mailed to the child care home providers of a day care program on March 23, 1988. Six questionnaires were returned within 2 weeks. After follow up by phone, another 12 questionnaires were submitted. Of the total 18 questionnaires, one was blank. 
The sample of child care center teachers was obtained from two workshops conducted by the health educator. Before each workshop, the author gave a short description of the study and distributed the questionnaire to those providers who were willing to participate in the study. Participants were asked to return the questionnaire after the workshop. One workshop was held on March 29, 1988, and four questionnaires were completed. The other workshop was held on April 5, 1988, and 19 questionnaires were obtained. From the questionnaires collected from child care teachers, one was a child care home provider and one questionnaire was blank, resulting in a total of 21 useable questionnaires. Thus, the total participants in this study were 39 , of which 21 were child care center teachers and 18 were child care home providers.

Data Analysis

Data were analyzed using both nominal and chi-square techniques. The personal data and health training needs data used percentages and nominal tables. The chi-square test was used to analyze health promotion behaviors. 


\section{Chapter 4}

\section{DATA ANALYSIS AND INTERPRETATION}

The results of this study will be described in three areas. The first area focuses on personal information data. The second area focuses on the results of the health promotion behaviors data which were analyzed using chi-square at the .05 level of significance. The results of the health training needs will be described by percentages.

Analysis of Personal Information Data

Personal information included age, formal education, early childhood education, health education in child care, first aid training, and frequency of reading. The child care center teachers and child care home providers had a different number of people in each sample. The total participants in the child care center teacher group was 21 and in the home provider group was 18 . The number of answered questions in each group was changed to percentages in order to do the comparison. The results of each item are shown as a table and interpreted on the following pages.

\section{Analysis of Age Data}

In Table 4, the age distribution data are given for child care center teachers and child care home providers. The largest portion of the center teachers fell between the ages of 20 to $29(52 \%)$, as compared to the home providers from ages 40 to $49(44 \%)$. This result may indicate that the job of home provider may be less attractive to younger people than those of the center teacher. It also may indicate that more mothers become home providers to earn extra money.

\section{Analysis of Formal Education Data}

In Table 5, formal education data of center teachers and home providers are given by number of people and percentages. All of the child care providers had at least a junior high school educational background. Forty-eight percent of the center teachers and $44 \%$ of the 
Table 4

Age Distribution of Center Teachers and Home Providers by Number and Percentage of People

\begin{tabular}{lllll}
\hline Year of age & $\begin{array}{l}\text { Center } \\
\text { Teachers }\end{array}$ & $\%$ & $\begin{array}{l}\text { Home } \\
\text { Providers }\end{array}$ & $\%$ \\
\hline under 20 & 2 & 9.5 & 1 & 5.6 \\
$20-29$ & 11 & 52.4 & 2 & 11.1 \\
$30-39$ & 2 & 9.5 & 6 & 33.3 \\
$40-49$ & 5 & 23.8 & 8 & 44.4 \\
over 50 & 1 & 4.8 & 1 & 5.6 \\
Total & 21 & $100 \%$ & 18 & $100 \%$ \\
\hline
\end{tabular}


Table 5

Formal Education of Center Teachers and Home Providers by Number and Percentage of People

\begin{tabular}{lllll}
\hline Education & $\begin{array}{l}\text { Center } \\
\text { Teachers }\end{array}$ & $\%$ & $\begin{array}{l}\text { Home } \\
\text { Providers }\end{array}$ & $\%$ \\
& 0 & 0.0 & 2 & 11.1 \\
Junior High & 10 & 47.6 & 8 & 44.4 \\
High & 8 & 38.1 & 5 & 27.8 \\
2 year College & 3 & 14.3 & 3 & 16.7 \\
4 year College & 21 & $100 \%$ & 18 & $100 \%$ \\
Total & & & & \\
\hline
\end{tabular}


home providers had graduated from high school. These results indicate that over half of both groups had high school education.

\section{Analysis of Early Childhood Education Data}

In Table 6, early childhood college education units results of center teachers and home providers are given by number and percentage of people. There were four home providers who did not answer this question. Those four were not counted in this section.

The major research question in this study asked if there is a difference in health promotion behaviors between child care center teachers, who have at least 12 postsecondary semester units of early childhood education or child development, and child care home providers, who are not required to have this education. It was assumed that all of the center teachers would have at least 12 college units of early childhood education in this study. However, the results showed that $38 \%$ of the center teachers did not have 12 college units of early childhood education. It must then be assumed that those teachers were employed prior to the licensing regulation which requires 12 college units of early childhood education. Also, $79 \%$ of the home providers did have at least one college unit of early childhood education which is not a licensing requirement for them. Twelve college units of early childhood education was the independent variable in this study, but eight child care center teachers did not have 12 college units of early childhood education which can be a bias for this study.

\section{Analysis of Health Education Related to Child Care Data}

In Table 7, the data results for workshops on health education related to child care taken by center and home providers are given by number and percentage of people. This was a multiple-choice question. Among those participants who did answer this question, $21 \%$ of the center teachers and $6 \%$ of the home providers did not have any health education related to child care. 
Table 6

Early Childhood Education Units of Center Teachers and Home Providers by Number and Percentage of People

\begin{tabular}{lllll}
\hline Units & $\begin{array}{l}\text { Center } \\
\text { Teachers }\end{array}$ & $\%$ & $\begin{array}{l}\text { Home } \\
\text { Providers }\end{array}$ & $\%$ \\
\hline 0 & 0 & 0.0 & 3 & 21.4 \\
$1-6$ & 3 & 14.3 & 3 & 21.4 \\
$7-12$ & 5 & 23.8 & 3 & 21.4 \\
Over 12 & 13 & 61.9 & 5 & 35.8 \\
Total & 21 & $100 \%$ & 14 & $100 \%$ \\
\hline
\end{tabular}


Table 7

Health Education Related to Child Care Taken by Center Teachers and Home Providers by Number and Percentage of People

\begin{tabular}{|c|c|c|c|c|}
\hline \multirow[t]{2}{*}{ Workshop } & \multicolumn{2}{|l|}{ Center } & \multicolumn{2}{|l|}{ Home } \\
\hline & Teachers & $\%$ & Providers & $\%$ \\
\hline Sanitation & 3 & 20.0 & 11 & 68.8 \\
\hline Nutrition & 8 & 53.3 & 16 & 100.0 \\
\hline Child Illness & 4 & 26.6 & 11 & 68.8 \\
\hline Safety & 10 & 66.6 & 9 & 56.3 \\
\hline Others & 2 & 13.3 & 4 & 25.0 \\
\hline None & 4 & -- & 2 & $\cdots$ \\
\hline Total Useable Samples & 15 & --- & 16 & $-\cdots$ \\
\hline
\end{tabular}

Note. Participants gave more than one answer for this question. 
In this study, the criterion to determine which of the health education workshops had a "high" or "low" participation rate within the child care providers was set at 50\%. Among those providers who had health education of child care, the "high" health education workshops attended by the center teachers (over $50 \%$ ) were nutrition and safety, whereas home providers (over 50\%) attended workshops on sanitation, nutrition, child illness, and safety.

These results indicate that center teachers participated in workshops on health education of child care less than home providers. It was assumed that home providers are isolated in their own homes and need to receive their health education outside, whereas center teachers have inservice health education within the agency.

\section{Analysis of First Aid Training Data}

Table 8 shows the number and percentage of center teachers and home providers who had first aid training experience. This was a multiple-choice question. Among the providers who did answer this question, $22.2 \%$ of the center teachers and $30.8 \%$ of the home providers did not have any first aid training. Among those providers who had first aid training, only adult first aid was taken by over $50 \%$ of the center teachers. In the home providers group, over $50 \%$ of the providers have taken adult first aid and children first aid. The results indicate that first aid training was not a learning priority for the center teachers and home providers.

\section{Analysis of Frequency of Reading Data}

The frequency of reading child care magazines and/or books by center teachers and home providers are given in Table 9. The results show that $61.0 \%$ of the home providers read magazines and/or books more than 1 hour a week, as compared to $47.6 \%$ of the center teachers. These results indicate that home providers do more reading in child care to improve themselves than center teachers. 
Table 8

First Aid Training of Center Teachers and Home Providers by Number and Percentage of People

\begin{tabular}{|c|c|c|c|c|}
\hline \multirow[t]{2}{*}{ First Aid Training } & \multicolumn{2}{|l|}{ Center } & \multicolumn{2}{|l|}{ Home } \\
\hline & Teachers & $\%$ & Providers & $\%$ \\
\hline Adult First Aid & 8 & 57.1 & 7 & 53.8 \\
\hline Children First Aid & 6 & 42.9 & 9 & 69.2 \\
\hline Infant Emergency Training & 3 & 21.4 & 6 & 46.2 \\
\hline 1987-1988 CPR * & 4 & 28.6 & 1 & 7.7 \\
\hline Others & 1 & 7.1 & 1 & 7.7 \\
\hline None & 4 & --- & 4 & --- \\
\hline Total Useable Samples & 14 & --- & 13 & --- \\
\hline
\end{tabular}

* $\mathrm{CPR}=$ Cardiopulmonary Resuscitation

Note. Participants gave more than one answer to this question. 
Table 9

Frequency of Reading Child Care Magzines/Books of Center Teachers and Home Providers by Number and Percentage of People

\begin{tabular}{lcccc}
\hline $\begin{array}{l}\text { Frequency of Reading } \\
\text { Weekly }\end{array}$ & $\begin{array}{l}\text { Center } \\
\text { Teachers }\end{array}$ & $\%$ & $\begin{array}{l}\text { Home } \\
\text { Providerd }\end{array}$ & $\%$ \\
\hline None & 0 & 0.0 & 1 & 5.6 \\
Less Than 1 Hour & 7 & 33.3 & 1 & 5.6 \\
1 Hour & 4 & 19.1 & 5 & 27.8 \\
More Than 1 Hour & 10 & 47.6 & 11 & 61.0 \\
Total & 21 & $100 \%$ & 18 & $100 \%$ \\
\hline
\end{tabular}




\section{Analysis of Health Promotion Behaviors Data}

The results of four health promotion behaviors were analyzed in this study. The health promotion behaviors were (a) balanced food supply, (b) sleep/rest requirements, (c) physical awareness, and (d) sanitation. The results of the chi-square test showed that sleep/rest requirements and handwashing, one of the sanitation behaviors, had a significant difference at the .05 level between center teachers and home providers. Other behaviors did not reveal a significant difference between the two groups. The statistical data for each behavior will be discussed

\section{Analysis of Nutritional Supply Data}

The daily nutritional needs for children should include milk, meat, vegetable, and bread or the equivalent food. In the questionnaire, questions 2 and 3 (Appendix $C$ ) were designed to evaluate whether or not the child care providers did provide a balanced diet consisting of the above four main nutrients for the children.

The criteria for a "correct" answer which would indicate health promotion behavior should include the four different food groups within questions 2 and 3. Twenty-one center teachers and 18 home providers answered these questions. The participants who chose OTHERS or DO NOT SERVE BREAKFAST/LUNCH were not counted in this section. Fifteen valid answers in the center group and 18 valid answers in the home group were counted.

Table 10 presents the combined answers on questions 2 and 3 for both groups. The chi-square of balanced food supply was 0.61 which did not reach the significance at $\mathrm{p}=.05$ level for one degree of freedom. The test revealed no difference between the two groups, and it also showed that $86 \%$ of the center teachers and $94 \%$ of the home providers did provide a balanced diet to the children. This result indicates that most of the providers did know the importance of a balanced diet and did provide a balanced diet to children. 
Table 10

Chi Square Test for Balanced Diet by Center Teachers' and Home Providers' Answers

\begin{tabular}{llclll}
\hline & $\begin{array}{l}\text { Center } \\
\text { Teachers }\end{array}$ & $(\%)$ & $\begin{array}{l}\text { Home } \\
\text { Providers }\end{array}$ & $(\%)$ & Total \\
Yes & 13 & $(86)$ & 17 & $(94)$ & 30 \\
No & 2 & $(14)$ & 1 & $(6)$ & 3 \\
Total & 15 & $(100)$ & 18 & $(100)$ & $x^{2}=0.61$ \\
\hline
\end{tabular}

Note. $X^{2}(1, \underline{N}=33)=0.61$

Not significant at .05 level. 


\section{Analysis of Sleep/Rest Awareness Data}

Daytime sleep/rest is essential for children after exploring and exerting boundless energy. In the questionnaire, questions 4 and 5 (Appendix C) were designed to assess whether or not the child care providers did set certain time limitations for toddlers and preschoolers to sleep or rest. Question 4 was designed for toddlers, and question 5 was designed for preschoolers.

The "correct" answers which indicate health promotion behaviors on both questions were either 1 HOUR OR LESS or MORE THAN 1 HOUR. All the center teachers and home providers answered question 4 and question 5 , but two center teachers chose the answer of NOT APPLICABLE in question 4. This indicates that those two teachers do not take care of toddlers in their child care setting. Therefore, those two teachers were not part of the chi-square analysis in question 4 . As a result, 19 center teachers' and 18 home providers' answers were calculated in question 4. Twenty-one center teachers' and 18 home providers' answers were counted in question 5.

The chi-square test was done on the sleep/rest requirement for toddlers and for preschoolers. The chi-square test for the sleep/rest requirements on question 4 which relates to toddlers was 10.41 (see Table 11). On question 5, which relates to preschoolers, the chi-aquare was 7.84 (see Table 12). Both results did reach significance at $\mathrm{p}=.05$ level for one degree of freedom. These results indicate that center teachers did provide a better sleep/rest schedule than home providers. These results may indicate a need for more education for home providers regarding sleep/rest requirements for toddlers and preschoolers. 
Table 11

Chi Square Test of Sleep/Rest Requirements for Toddlers (Age 1-3) from Center Teachers' and Home Providers' Answers

\begin{tabular}{llllll}
\hline $\begin{array}{l}\text { Sleep/Rest } \\
\text { Requirement }\end{array}$ & $\begin{array}{l}\text { Center } \\
\text { Teachers }\end{array}$ & $(\%)$ & $\begin{array}{l}\text { Home } \\
\text { Providers }\end{array}$ & $(\%)$ & Total \\
\hline Yes & 17 & $(89.5)$ & 7 & $(38.9)$ & 24 \\
No & 2 & $(10.5)$ & 11 & $(61.1)$ & 13 \\
Total & 19 & $(100)$ & 18 & $(100)$ & $x^{2}=10.41$ \\
\hline
\end{tabular}

Note. $\chi^{2}(1, \underline{\mathrm{N}}=37)=10.41, \underline{\mathrm{p}}<.05$ 
Table 12

Chi Square Test of Sleep/Rest Requirements for Preschoolers (Age 4-6) from Center Teachers' and Home Providers' Answers

\begin{tabular}{llllll}
\hline $\begin{array}{l}\text { Sleep/Rest } \\
\text { Requirement }\end{array}$ & $\begin{array}{l}\text { Center } \\
\text { Teachers }\end{array}$ & $(\%)$ & $\begin{array}{l}\text { Home } \\
\text { Providers }\end{array}$ & $(\%)$ & Total \\
\hline Yes & 19 & $(90.5)$ & 9 & $(50.0)$ & 28 \\
No & 2 & $(9.5)$ & 9 & $(50.0)$ & 11 \\
Total & 21 & $(100)$ & 18 & $(100)$ & $\chi^{2}=7.84$ \\
\hline
\end{tabular}

Note. $\chi^{2}(1, \underline{N}=39)=7.84, \underline{p}<.05$ 


\section{Analysis of Physical Awareness Data}

The category of physical awareness includes questions regarding immunization and dental care. The specific questions were questions 6 and 7. The results are presented as follows.

\section{Analysis of Immunization Data}

In the child care setting, child care providers should follow up each child's immunization record using the recommendations of the Immunization Unit, California Department of Health Services (State of California Department of Health Services, 1986). In the questionnaire, question 6 (Appendix $\mathrm{C}$ ) was designed to evaluate whether or not the child care providers did check each child's immunization record annually.

The answer of LESS THAN ONCE A YEAR or ONCE A YEAR was considered a "correct" answer or health promotion behavior. Nineteen center teachers and 18 home providers responded to question 6.

The chi-square test was done for follow up on immunization records for both groups. The result was 3.45 , which did not reach the siginificant level at $\mathrm{p}=.05$ for one degree of freedom (see Table 13). There was no siginificant difference between center teachers and home providers. However, the results did reveal that $5.3 \%$ of the center teachers and $27.8 \%$ of the home providers did not check each child's immunization record annually. This result indicates a need for education regarding the importance of immunization followup in child care settings.

\section{Analysis of Dental Care Data}

Helping children to brush their teeth after eating can reduce the probability of caries. In the questionnaire, question 7 (Appendix C) was designed to assess whether or not the providers do ask children to brush their teeth after eating. 
Table 13

Chi Square Test of Follow Up Immunization Record for Children from Center Teachers' and Home Providers' Answers

\begin{tabular}{|c|c|c|c|c|c|}
\hline Follow Up & $\begin{array}{l}\text { Center } \\
\text { Teachers }\end{array}$ & $(\%)$ & $\begin{array}{l}\text { Home } \\
\text { Providers }\end{array}$ & $(\%)$ & Total \\
\hline Yes & 18 & (94.7) & 13 & $(72.2)$ & 31 \\
\hline No & 1 & (5.3) & 5 & $(27.8)$ & 6 \\
\hline Total & 19 & $(100)$ & 18 & $(100)$ & $x^{2}=3.45$ \\
\hline
\end{tabular}

Note. $\chi^{2}(1, \underline{N}=37)=3.45$

Not significant at .05 level. 
The "correct" answer which would indicate health promotion behavior should be AFTER EVERY MEAL/SNACK. Twenty center teachers and 18 home providers answered this question.

The chi-square test was used and the result for dental care was 2.37 (see Table 14) which did not reach the siginificant level at $\mathrm{p}=.05$ for one degree of freedom. In addition, $100 \%$ of the center teachers and $88.9 \%$ of the home providers did not give the "correct" answer which would indicate health promotion behavior. This result indicates that brushing was done less frequently or not at all. Ideally, children's teeth should be brushed after eating. However, it might not be feasible or practical in the child care setting. Further research is needed to discover a balance between ideal and feasible teeth brushing in the child care enviroment.

\section{Analysis of Sanitation Data}

Proper sanitation, which includes surface disinfection and handwashing in the child care setting, can reduce the spread of disease. Disinfectant solution, disinfected surfaces, frequency of surface disinfection, and handwashing were studied in this section. In the questionnaire, questions 9 through 12 were designed to evaluate whether or not the child care providers do apply the correct sanitation method in the child care setting. Analysis of Disinfectant Solution Data

The most effective sanitation activity is to use soap and water to wash surfaces and a fresh bleach solution (1/4 cup bleach per gallon of water) to disinfect the surfaces. Question 9 was designed to assess whether or not the providers do apply the sanitation activity recommended by the Centers for Disease Control (1985) to clean their child care setting.

The "correct" answers are both BLEACH AND WATER and SOAP AND WATER. Twenty-one center teachers and 18 home providers responded to this question. 
Table 14

Chi Square Test of Dental Care for Children from Center Teachers' and Home Providers' . Answers

\begin{tabular}{llllll}
\hline & Center & & & \\
Teachers & $(\%)$ & Pome \\
Providers & $(\%)$ & Total \\
\hline Yes & 0 & $(0.0)$ & 2 & $(11.1)$ & 2 \\
No & 20 & $(100)$ & 16 & $(88.9)$ & 36 \\
Total & 20 & $(100)$ & 18 & $(100)$ & $\chi^{2}=2.37$ \\
\hline
\end{tabular}

Note. $X^{2}(1, \underline{N}=38)=2.37$

Not significant at .05 level. 
The chi-square test for disinfectant solution was 1.08 which did not reach siginificance at $\mathrm{p}=.05$ level for one degree of freedom (see Table 15). There was no significant difference between center teachers and home providers on this question. The results show that $85.7 \%$ of the center teachers and $72.2 \%$ of the home providers did not use the "correct" solution to clean their child care setting. These results indicate that continued education is needed for both groups.

\section{Analysis of Disinfected Surfaces Data}

The surfaces contaminated by staff and children include faucet handles, toilet seats, floors, doorknobs, low shelves, tables, counters, and toys. These surfaces should be cleaned regularly. Question 10 was designed to evaluate whether or not the providers did clean these surfaces.

A "correct" answer would include all the equipment listed on question 10. Twentyone center teachers and 18 home providers answered this question.

The chi-square test results for disinfected surfaces was 0 which did not reach significance at $\mathrm{p}=.05$ level for one degree of freedom (see Table 16). There was no significant difference between the two groups. Seventy-one percent of the center teachers and $72 \%$ of the home providers did not answer the question correctly. Lack of sanitaion awareness could cause an increase in the spread of infectious diseases among the children. Analysis of Frequency of Surface Disinfection Data

According to the recommendations from the Centers for Disease Control (1985), surfaces in the bathroom should be cleaned and disinfected more than once a day, if possible. Surfaces that infants and young toddlers are likely to touch should be washed every day. Floors, low shelves, and doorknobs should be washed and disinfected every week. Question 11 was designed to evaluate whether or not the providers did apply these principles to clean the equipment in the child care setting. 
Table 15

Chi Square Test of Disinfectant Solution from Center Teachers' and Home Providers' Answers

\begin{tabular}{llllll}
\hline $\begin{array}{l}\text { Disinfectant } \\
\text { Solution }\end{array}$ & $\begin{array}{l}\text { Center } \\
\text { Teachers }\end{array}$ & $(\%)$ & $\begin{array}{l}\text { Home } \\
\text { Providers }\end{array}$ & $(\%)$ & Total \\
\hline Correct & 3 & $(14.3)$ & 5 & $(27.8)$ & 8 \\
Incorrect & 18 & $(85.7)$ & 13 & $(72.2)$ & 31 \\
Total & 21 & $(100)$ & 18 & $(100)$ & $x^{2}=1.08$ \\
\hline
\end{tabular}

Note. $X(1, \underline{N}=39)=1.08$

Not significant at .05 level. 
Table 16

Chi Square Test of Disinfected Surfaces from Center 'Teachers' and Home Providers' Answers

\begin{tabular}{llllll}
\hline $\begin{array}{l}\text { Disinfected } \\
\text { Surfaces }\end{array}$ & $\begin{array}{l}\text { Center } \\
\text { Teachers }\end{array}$ & $(\%)$ & $\begin{array}{l}\text { Home } \\
\text { Providers }\end{array}$ & $(\%)$ & Total \\
\hline Correct & 6 & $(28.6)$ & 5 & $(27.8)$ & 11 \\
Incorrect & 15 & $(71.4)$ & 13 & $(72.2)$ & 28 \\
Total & 21 & $(100)$ & 18 & $(100)$ & $\varkappa^{2}=0$ \\
\hline
\end{tabular}

Note. $\chi^{2}(1, \underline{N}=39)=0$

Not significant at .05 level. 
The "correct" answers are MORE THAN ONCE PER DAY on toilet seats and tables and ONCE PER DAY on faucet handles, toys, and counters. Floors and doorknobs should be cleaned ONCE PER WEEK. Twenty center teachers and 18 home providers answered this question.

The chi-square test results for faucet handles, toilet seats, floors, tables, doorknobs, counters, and toys were $0.85,1.55,0.00,2.90,0.63,1.16$, and 1.97 , respectively, and did not reach significance at $\mathrm{D}=.05$ level for one degree of freedom. In Table 17, frequency data for surface disinfection from center teachers' and home providers' answers are given by number of people. The center teachers' answers for the cleaning of toilet seats and toys were over 50\% incorrect indicating that they were either unaware of the importance of cleaning these surfaces or did not consider them a priority. The home providers' answers for cleaning toys were over $50 \%$ incorrect. These results for both groups indicate that continued education is needed for both groups in behalf of the children in order to promote their health.

Analysis of Handwashing Data

Proper handwashing is the best way to reduce disease. Question 12 (Appendix C) was designed to assess whether or not the providers do wash their hands under the situations recommended by State of California Department of Health Services, Infectious Disease Branch (1986).

The "correct" answer for center teachers would include all of the situations listed on question 12. Home providers should respond the same except WHEN ARRIVE AT CHILD CARE SETTING. Twenty-one center teachers and 18 home providers answered this question. 
Table 17

Frequency Data for Disinfection of Surfaces from Center Teachers' and Home Providers' Answers by Number of People

\begin{tabular}{|c|c|c|c|c|c|c|}
\hline \multirow[t]{3}{*}{ Surfaces } & \multicolumn{3}{|c|}{$\begin{array}{l}\text { Center } \\
\text { Teachers }\end{array}$} & \multicolumn{2}{|c|}{$\begin{array}{l}\text { Home } \\
\text { Providers }\end{array}$} & \multirow[b]{3}{*}{ No * } \\
\hline & \multicolumn{3}{|c|}{$N=20$} & \multicolumn{2}{|c|}{$N=18$} & \\
\hline & Correct & Incorrect & No* & Correct & Incorrect & \\
\hline Faucet Handles & 15 & 5 & 0 & 11 & 7 & 0 \\
\hline Toilet Seats & 9 & 9 & 2 & 12 & 5 & 1 \\
\hline Floors & 20 & 0 & 0 & 18 & 0 & 0 \\
\hline Tables & 17 & 3 & 0 & 18 & 0 & 0 \\
\hline Door Knobs & 12 & 8 & 0 & 13 & 5 & 0 \\
\hline Counters & 20 & 0 & 0 & 17 & 1 & 0 \\
\hline Toys & 5 & 15 & 0 & 8 & 9 & 1 \\
\hline
\end{tabular}

* No response 
The chi-square test results for handwashing for both groups was 5.68 which did reach significance at $\mathrm{p}=.05$ level for one degree of freedom (see Table 18). The results reveal that home providers had better handwashing behaviors than center providers. Having more flexible time in a home setting could be the reason for this result. However, further study is needed.

\section{Summary}

Child care center teachers are required to have 12 early childhood education units in order to work in a child care center. Of the 21 child care teachers in this study, $38 \%$ did not have the 12 required college units. This lack of units might have influenced the results of this study. The only health promotion behavior which was higher for the center teachers than home providers was the knowledge of sleep/rest requirements for toddlers and preschoolers. Both center teachers and home providers scored low on dental health and sanitation behaviors. The results might indicate a need for education and monitoring to make sure that these activities are carried out in the child care setting. The results for dental health and sanitation might also have been due to the strict criteria for "correct" answers which were set for this study. 
Table 18

Chi Square Test of Handwashing from Center Teachers' and Home Providers' Answers

\begin{tabular}{llllll}
\hline Handwashing & $\begin{array}{l}\text { Center } \\
\text { Teacher }\end{array}$ & $(\%)$ & $\begin{array}{l}\text { Home } \\
\text { Providers }\end{array}$ & $(\%)$ & Total \\
\hline Correct & 6 & $(28.6)$ & 12 & $(66.7)$ & 18 \\
Incorrect & 15 & $(71.4)$ & 6 & $(33.3)$ & 21 \\
Total & 21 & $(100)$ & 18 & $(100)$ & $x^{2}=5.68$ \\
\hline
\end{tabular}

Note. $X(1, \underline{N}=39)=5.68, \underline{p}<.05$ 
Analysis of Health Training Needs Data

The questionnaire was also designed to assess the participants' needs for first aid training and health education. The results are divided into first aid training needs and health education needs.

\section{Analysis of First Aid Training Needs Data}

Question 13 (Appendix C) was designed to investigate the providers' need for first aid training. Eighteen center teachers and 18 home providers answered this question. The question asked if providers believed they had enough first aid training to handle the immediate emergency care of the children in their child care settings. Sixty-seven percent of the center teachers and $50 \%$ of the home providers thought that they did not have enough first aid training (see Table 19).

The responses for those center teachers $(\mathrm{N}=12)$ and home providers $(\mathrm{N}=9)$ who felt they needed additional first aid training were divided among the eight areas: (a) bleeding, (b) head injury, (c) drowning, (d) airway obstruction, (e) broken bones, (f) burns, (g) shock, and (h) others. Table 20 shows the percentage distribution for these areas.

In this study, any area that had a $50 \%$ or above response rate was considered an area of concern by the center teachers and home providers. The concern areas among center teachers were: (a) head injury, (b) drowning, (c) airway obstruction, (d) broken bones, and (e) shock. Whereas, the home providers indicated concern regarding shock only. The results indicate that center teachers have more concerns regarding additional first aid training.

\section{Analysis of Health Education Needs Data}

Question 14 (Appendix C) was a multiple-choice question which was designed to evaluate the participants' needs for health education. Eighteen center teachers and 18 home 
Table 19

Enough First Aid Training from Center Teachers' and Home Providers' Answers by Number and Percentage of People

\begin{tabular}{cllll}
\hline $\begin{array}{c}\text { Enough } \\
\text { First Aid Training }\end{array}$ & $\begin{array}{l}\text { Center } \\
\text { Teachers }\end{array}$ & $\%$ & $\begin{array}{l}\text { Home } \\
\text { Providers }\end{array}$ & $\%$ \\
\hline Yes & 6 & 33.3 & 9 & 50.0 \\
No & 12 & 66.7 & 9 & 50.0 \\
Total & 18 & 100.0 & 18 & 100.0 \\
\hline
\end{tabular}


Table 20

Areas of First Aid Training Needs of Center Teachers and Home Providers by Number and Percentage of People

\begin{tabular}{|c|c|c|c|c|}
\hline \multirow{2}{*}{ Areas } & \multicolumn{2}{|c|}{$\begin{array}{l}\text { Center } \\
\text { Teachers }\end{array}$} & \multicolumn{2}{|c|}{$\begin{array}{l}\text { Home } \\
\text { Providers }\end{array}$} \\
\hline & $N=12$ & $\%$ & $\mathrm{~N}=9$ & $\%$ \\
\hline Bleeding & 5 & 41.7 & 2 & 22.2 \\
\hline Head Injury & 7 & 58.3 & 4 & 44.4 \\
\hline Drowning & 7 & 58.3 & 1 & 11.1 \\
\hline Airway Obstruction & 8 & 66.7 & 4 & 44.4 \\
\hline Broken Bones & 6 & 50.0 & 3 & 33.3 \\
\hline Burns & 5 & 41.7 & 3 & 33.3 \\
\hline Shock & 6 & 50.0 & 5 & 55.6 \\
\hline Others & 1 & 8.3 & 1 & 11.1 \\
\hline
\end{tabular}

Note. Participants could check more than one area in this question. 
providers answered this question. Table 21 presents the percentage distribution for the topics in which the participants wanted further information.

Again, the results indicate that center teachers had a higher interest in all the topics of health education than home providers except for child development. Center teachers are required to have 12 units of early childhood education. Therefore, they may not see a need for any more early childhood education.

The center teachers responded to more of the educational topics than did the home providers. These responses are similar to the results on first aid training areas. The perceived need for more education might be due to the differences in the career goals of the two groups. The center teachers have chosen child care as a vocation, whereas home providers might be doing child care out of economic necessity and have less interest in perfecting their skills. The differences in responses could also be attributed to the number of children the two groups have in their care. Home providers are responsible for a smaller group of children which limits diversity. Hence, maybe it decreases the perceived need for more education. 
Table 21

Topics of Health Education Needs of Center Teachers and Home Providers by Number and Percentage of people

\begin{tabular}{|c|c|c|c|c|}
\hline \multirow[t]{2}{*}{ Topics } & \multicolumn{2}{|c|}{$\begin{array}{l}\text { Center } \\
\text { Teachers }\end{array}$} & \multicolumn{2}{|c|}{$\begin{array}{l}\text { Home } \\
\text { Providers }\end{array}$} \\
\hline & $N=18$ & $\%$ & $N=18$ & $\%$ \\
\hline Handwashing & 4 & 22.2 & 0 & 0.0 \\
\hline Child Development & 8 & 44.4 & 10 & 55.6 \\
\hline Play and Rest & 9 & 50.0 & 4 & 22.2 \\
\hline Dental Care & 7 & 38.9 & 3 & 16.7 \\
\hline Accident Prevention & 13 & 72.2 & 7 & 38.9 \\
\hline Daily Health Inspection & 8 & 44.4 & 0 & 0.0 \\
\hline Emergency Training & 10 & 55.6 & 9 & 50.0 \\
\hline Sanitation & 7 & 38.9 & 2 & 11.1 \\
\hline Nutrition & 8 & 44.4 & 2 & 11.1 \\
\hline Immunizations & 8 & 44.4 & 4 & 22.2 \\
\hline Child Abuse & 13 & 72.2 & 5 & 27.8 \\
\hline First Aid & 10 & 55.6 & 8 & 44.4 \\
\hline Safety & 8 & 44.4 & 4 & 22.2 \\
\hline Others & 1 & 5.6 & 0 & 0.0 \\
\hline
\end{tabular}

Note. Participants could check more than one topic on this question. 


\section{Chapter 5}

\section{CONCLUSIONS AND RECOMMENDATIONS}

This study provided preliminary data to identify the health promotion behaviors of child care center teachers and child care home providers. The main assumption of this study was that the 12 post-secondary semester units of early childhood education required for the center teachers had little positive impact on their health promotion behaviors. Both center teachers and home providers indicated the need for additional health education on child care and first aid training regardless of their educational background.

Conclusions

The statistical data of this study revealed several phenomena which are described as follows:

1. The majority of the center teachers were 20 to 29 years old and home providers were 40 to 49 years old. These data indicate that younger people tended to work outside their home.

2. Most of the center teachers and home providers had at least a high school diploma. Also, the home providers tended to increase their knowledge of child care through workshops and reading, whereas center teachers attended first aid training classes more than home providers.

3. Most of the center teachers and home providers could provide a balanced diet to children. This result reflects that the public resources of nutrition have been utilized by the child care providers sufficiently.

4. Center teachers identified the sleep/rest requirements correctly whereas home providers did not. These results indicate that home providers need more information on scheduling the activities/rest for the children. 
5. Most of center teachers and home providers did check each child's immunization record at least annually. Thus, the recommendations of the Centers for Disease Control (1985) regarding immunizations have been implemented by these child care providers. However, the effectiveness of these actions was not studied in this study.

6. All center teachers and most of the home providers indicated that little attention was given to help children brush their teeth after eating. However, according to the data on the needs of child care providers regarding health education, less than $50 \%$ of the center teachers and home providers were interested in the topic of dental care. Lack of time, awareness, or parent's cooperation could be the possible reasons for this lack of attention to dental needs of young children. But, more studies need to be done in order to get a clearer picture of this subject.

7. The frequency for disinfection of toys was missed by over $50 \%$ of the center teachers and home providers. Also, over $50 \%$ of the center teachers and home providers did not use the proper solutions for sanitation. These solutions were soap and water and bleach mixed with water. These solutions should be used regularly to clean areas such as faucet handles and doorknobs. These results indicate that more health education regarding sanitation for the child care providers should be addressed by health professionals. Again, fewer than $50 \%$ of the center teachers and home providers showed any interest in sanitation. This result reveals a conflict between the needs of children and child care providers.

8. Center teachers showed more interest in first aid training than did the home providers. The most popular first aid training areas among child care center teachers (over $50 \%$ ) were airway obstruction, head injury, drowning, broken bones, and shock. In addition, home providers (over 50\%) were interested in shock only. It was assumed that children in center settings had more outdoor activities than those in home settings. 
9. Center teachers were more interested in all of the health education topics listed on guestion 14, whereas home providers were only interested in the topic of child development. Center teachers have required child development classes and might not need additional child development content.

\section{Limitations}

The limitations for this study center around the sample and questionnaire. Each will be discussed.

\section{Sample Limitations}

1. It was not feasible to get permission to conduct this study widely due to the policy of several child care institutions. Therefore, the sample for this study was restricted to a day care program and workshops conducted by a public health nurse where permission could be gained.

2. The two methods of data collection in center group and home group could be a bias to this study. Home providers returned the questionnaire by mail. It was assumed that those participants in the home group who responded were concerned with the problems of child care and wanted to improve the quality of their child care. However, the questionnaires for the center teachers were completed in a workshop. The return rate in the center group was higher than those in the home group. The center group could be more representative of the population of center teachers than the sample of the home group.

3. The results of this study can only represent the groups in this study. They cannot be generalized to a larger population or to another county or state because of the small sample. 


\section{Questionnaire Limitations}

1. The questionnaire was written in English. Many of the home providers could not read English; therefore, they were not included in this study. Only English speaking providers could participate.

2. The draft form of the questionnaire was only reviewed by one child care provider in this study. The validity and reliability of the questionnaire would have been higher if more child care providers were asked to participate in the review of the questionnaire.

\section{Recommendations}

This study identified many phenomena which need further study. According to the results and the experience gained from this study, there are several recommendations for those who are concerned with the quality of child care and for those who are interested in doing a similar study:

1. The questionnaire should be completed and returned before the workshop starts because the content of the workshop could affect the participant's answer.

2. A similar study could be conducted with a larger sample in order to determine the reliability of the results.

3. Health professionals could convey more information on sanitation and dental care to the providers through workshops, newsletters, and visits in order to increase the awareness of the providers and to benefit children.

4. Policy makers of child care licensing should consider health education as one of the requirements for both center teachers and home providers in order to assure the qualification of child care providers and the quality of child care for the society. Another alternative could be to make health education of child care a requirement for renewing the licensing. 
5. Conclusions 6 and 7 on page 51 indicate that there are conflicts between lack of health promotion behaviors and interest in health training among the child care providers. The reason for these conflicts may not only be a lack of awareness. Therefore, the role of health professionals is not only to provide the health information to child care providers, but also to research the problems in the child care field. Other areas which could be studied are (a) how to make child care providers feel the importance of their profession and (b) how to make the health knowledge of child care providers become effective practical behaviors. 
References 


\section{References}

Alston, F. K. (1984). Caring for other people's children: A complete guide to family day care. Baltimore: University Park Press.

Blanding, J. A. (1987). Health promotion in child care: A study of the effectiveness of an educational intervention on child care providers. Unpublished master's thesis, San Jose State University, San Jose, CA.

Centers for Disease Control. (1985). What you can do to stop disease in child care centers. Atlanta, GA.

Christiansen, K. E. (1981). The determinants of health promoting behavior. Unpublished doctoral dissertation, Rush University, Chicago, $\mathbb{L}$.

Dennis, L. B., \& Hassol, J. (1983). Introduction to human development and health issues. Philadelphia: W. B. Saunders.

Dychtwald, K. (Eds.). (1986). Wellness and health promotion for the elderly. Rockville, MD: Aspen Publication.

Fleming, D. W., Cochi, S. L., Hightower, A. W., \& Broome, C. V.(1987). Childhood upper respiratory track infections: To what degree is incidence affected by day-care attendance? Pediatrics, $\underline{79}$, 55-60.

Harris, A. C. (1986). Child development. St. Paul, MN: West Publishing Co.

Haskins, R., \& Kotch, J. (1986). Day care and illness: Evidence, costs, and public

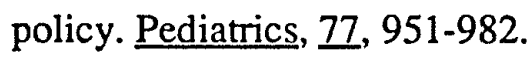

Kelly, B., Sein, C., \& McCarthy, P. L. (1987). Safety education in a pediatric primary care setting. Pediatrics, $\underline{79}$, 818-823.

Marlow, D. R. (1978). Textbook of pediatric nursing. Philadelphia: W. B. Saunders.

Murray, R. B., \& Zentner, J. P. (1985). Nursing assessment and health promotion through the life span (3rd ed.). Englewood Cliffs, NJ: Prentice-Hall. 
Noravath, N., Douse, J., \& Skinner, R. (1986). The development of a health education program in early childhood oral health. Patient Education and Counseling, $\underline{\text { 8, 63-72. }}$

Pender, N. J. (1982). Health promotion in nursing practice. East Norwalk, CT: PrenticeHall, Inc.

Pringle, S. M., \& Ramsey, B. E. (1982). Promoting the health of children. St. Louis: C. V. Mosby.

Reinisch, E. H., \& Minear, R. E., Jr. (1978). Health of the preschool child. New York: John Wiley \& Sons.

Rowan, C. T., \& Mazie, D. M. (1985, June). Day care in America: A special report. Reader's Digest, pp. 103-108.

State of California Department of Health Services, Infectious Disease Branch. (1986). What you can do to stop disease in your child care center or family child care home. Berkeley, CA.

Taylor, R. B., Ureda, J. R., \& Denham, J. W. (Eds.). (1982). Health promotion: Principles and clinical applications. Norwalk, CN: Appleton-Century-Crofts.

Title 22, Division 12, Chapter 2, Child Care Centers, Subchapter 1, Basic Requirements; State of California, Health and Welfare Agency, Department of Social Services; July 1985.

Title 22, Division 12, Chapter 3, Family Day Care Homes For Children, Basic Requirements; State of California, Health and Welfare Agency, Department of social Services; July 1985.

U.S. Bureau of the Census (1982). Trends in child care arrangements of working mothers (Current Population Reports Series P-23, no. 117). Washington, DC: U.S. Government Printing Office. 
U.S. Department of Health and Human Services (1981). Better health for our children: A national strategy (DHHS Publication No. 79-55071). Washington, DC: U.S. Government Printing Office. 
Appendix A

Cover Letter 
Dear Child-Care Provider,

I am a master's student at San Jose State University and I am working on my thesis to fulfill the requirements for my degree. I had the pleasure of meeting some of you when I conducted a pilot study on job satisfaction among child care providers while working with Judy Blanding, PHN during my field experience. Your assistance was greatly appreciated during that study. I would now like to invite you to participate in my thesis study on " A study to assess the health promotion behaviors and health training needs of child care center teachers and child care home providers".

My goal is to use the results of this study to influence the decisions of legislators, policy makers, and health professionals in order to benefit the child care field.

A survey is attached to this letter. It has a number in the upper right hand corner to represent you. But the number is only for my own record and your answers will not be shown to others. The results in this survey will be reported as a group.

If you decide to participate in this study, please sign the consent form on the next page, complete the survey and mail it back to me in the reply paid envelope within two weeks. If you have any questions regarding this study I can be reached at (415) 683-9419.

Thank you in advance for your participation.

Sincerely,

Anna Lu 
Appendix B

Consent Form 


\section{AGREEMENT TO PARTICIPATE IN RESEARCH}

AT SAN JOSE STATE UNIVERSITY

RESPONSIBLE INVESTIGATOR: ANNA LU

\section{TITLE OF PROTOCOL: A STUDY TO ASSESS THE HEALTH PROMOTION BEHAVIORS AND HEALTH TRAINING NEEDS OF CHILD CARE CENTER TEACHERS AND CHILD CARE HOME PROVIDERS}

I have been asked to participate in a research study that is investigating the health promotion behaviors and health training needs of child care providers. The results of this study should further our understanding of whether or not educational requirements are necessary to improve the quality of child care.

I understand that

1) I will be asked to fill out a survey and it will take about 10 minutes to complete.

2) There are no risks of this study.

3) There are no direct benefits of this study to me but the information will provide assistance to health care professionals in planning educational programs for child care providers.

4) There are no alternative procedures in this study except completing the questionnaire.

5) The results from this study may be published, but any information from this study that can be identified with me will remain confidential and will be disclosed only with my permission or as required by law.

\section{CONTINUED ON BACK. PLEASE SIGN BEFORE COMPLETING QUESTIONNAIRE}


6) There is no compensation in this study.

7) Any questions about my participation in this study will be answered by Anna Lu at (415) 683-9419. Complaints about the procedures may be presented to Sharon Hogan, Department of Nursing at (408) 924-3134. For questions or complaints about research subject's rights, or in the event of research-related injury, contact Serena Stanford, Ph.D. (Associate Academic Vice President for Graduate Studies) at (408) 924-2480.

8) My consent is given voluntarily without being coerced; I may refuse to participate in this study or in any part of this study, and I may withdraw at any time, without prejudice to my relations with SJSU.

9) I have received a copy of this consent form for my file.

I HAVE MADE A DECISION WHETHER OR NOT TO PARTICIPATE. MY SIGNATURE INDICATES THAT I HAVE READ THE INFORMATION PROVIDED ABOVE AND THAT I HAVE DECIDED TO PARTICIPATE.

DATE

SUBJECT'S SIGNATURE

INVESTIGATOR'S SIGNATURE 
Appendix C

Questionnaire 
If you are a child care center teacher or child care home provider, please fill out this survey. Otherwise, please disregard it. Thank you! 


\section{Questionnaire}

Personal Information: (please check the appropriate answer)

Title:

a child-care center teacher

$\square$ child-care home provider

Age:

a under 20

D 20.29

a $30-39$

口 40.49

口 50 or over

Formal education completed:

a none

finished junior high school

a finished 2 year college

a finished grammar school

a finished high school

a finished 4 year college or above

Education related to early childhood education (Formal college courses for credit):
a none
- $1-6$ units
7-12 units
over 12 units

Previous health education related to child care (workshop, etc.)

none

nutrition

a sanitation

D safely

a children's illnesses

others

Courses or workshops in first aid training: (The answer could be more than one)
none
- Adult's First Aid
C Children's First Aid
- Infant Emergency Training
口 1987-1988 CPR (Cardiopulmonary Resuscitation)
a Others

Frequency of reading magazine/books related to child care:

a none

- less than 1 hour a week

- 1 hour a week

a more than 1 hour a week 
There are no right or wrong answers to the questions below.

Please check the appropriate items. You may mark more than one item, if it is appropriate.

1. Do you or your center belong to any food program?

a yes a no

2. Below are several foods. Please mark the boxes by the foods which would be included in a typical breakfast at your facility.

$\begin{array}{llll}\square \text { milk } & \square \text { meat, poultry, fish } & \square \text { vegetables } & \square \text { bread } \\ \square \text { pudding } & \square \text { peanut butter } & \square \text { fruits } & \square \text { cracker } \\ \square \text { yogurt } & \square \text { beans } & \square \text { juice } & \square \text { cereal } \\ \square \text { cheese } & \square \text { eggs } & \square \text { noodles } \\ \square \text { others } & & \end{array}$

3. Below are several foods. Please mark the boxes by the foods which would be included in a typical lunch at your facility.

$\begin{array}{llll}\square \text { milk } & \square \text { meat, poultry, fish } & \square \text { vegetables } & \square \text { bread } \\ \square \text { pudding } & \square \text { peanut butter } & \square \text { fruits } & \square \text { cracker } \\ \square \text { yogurt } & \square \text { beans } & \square \text { juice } & \square \text { cereal } \\ \square \text { cheese } & \square \text { eggs } & \square \text { noodles } \\ \square \text { others } & & & \end{array}$

4. How many hours do you require toddlers (age 1-3) to take a nap or rest?
a no requirement
a 1 hour or less
a more than 1 hour
a no time limitation
- not applicable

5. How many hours do you require preschoolers (age 4-6) to take a nap or rest?
$\square$ no requirement
a more than 1 hour
a 1 hour or less
a no time limitation

not applicable 
6. How often do you update each child's immunization record?
a none
- less than once a year
a once a year
a more than once a year

7. When do you ask children to brush their teeth? (Please check all boxes that apply.)
$\square$ after every meal
- after every meal/snack
a after every snack
not at all
once a day
others, please describe

8. Do you brush your teeth the same as you ask the children?
$\square$ yes
口 no

9. What kind of solution do you use to clean your child-care setting?
(]) none
$\square$ bleach
口 soap and water
detergent
o others
a bleach and water
water

10. What kind of equipment in your child-care setting do you clean regularly?
- faucet handles
a floors
toilet seats
a door knobs
a tables
toys
a counters
$\square$ others

11. How do you clean the following equipment?

(Please $X$ in appropriate box.)

\begin{tabular}{|l|l|l|l|l|l|}
\hline & $\begin{array}{c}\text { More than } \\
\text { once per day }\end{array}$ & $\begin{array}{c}\text { once } \\
\text { per day }\end{array}$ & $\begin{array}{c}\text { every } \\
\text { other day }\end{array}$ & $\begin{array}{c}\text { once } \\
\text { per week }\end{array}$ & other \\
\hline faucet handles & & & & & \\
\hline toilet seats & & & & & \\
\hline floors & & & & & \\
\hline tables & & & & & \\
\hline corknobs & & & & & \\
\hline counters & & & & & \\
\hline toys & & & & & \\
\hline others & & & & & \\
\hline
\end{tabular}


12. In which of the following situations do you wash your hands? (You may mark as many as apply to you.)

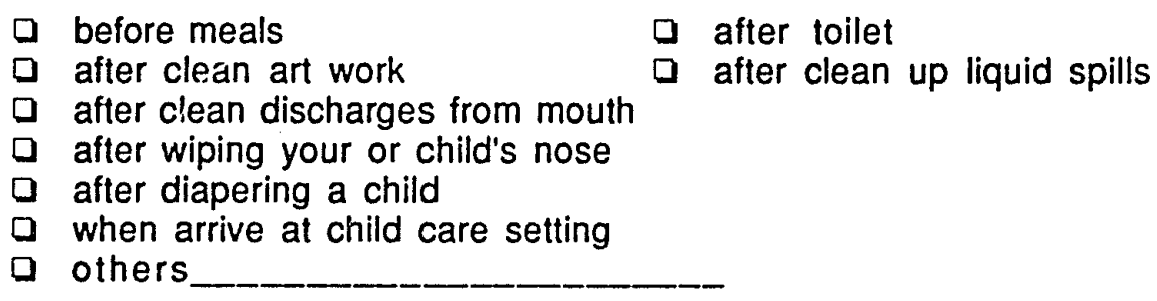

13. Do you feel that you have enough first aid training to handle the immediate emergency care of the children in your child care setting?

$\square$ yes $\square$ no

(If the answer is no, please mark the specific areas in which you need additional training)
bleeding
$\square$ head injury
broken bones
a drowning
a burns
a airway obstruction
a shock
others

14. Would you like further information about the following topics?

(Please check all topics of interest.)
$\square$ handwashing
a child development
- play and rest
a sanitation
- dental care
a nutrition
$\checkmark$ accident prevention
a immunizations
a child abuse
a daily health inspections
a emergency training (fire, flood, etc.)
others

Check if you would like a summary of the findings of this study

(If the answer is yes, please leave your name and address below)
nes 


\section{Appendix D}

\section{Permission Letter from Santa Clara County}

Health Department Director of Nursing 


\section{California}

February 16, 1988

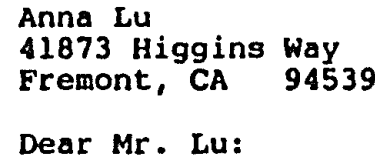

I have reviewed the questionneire for your theois, "A study to Arsezs the Health Promotion Behaviors and Health Fraining Need of Child Care Center Teachers and Child Care Home providers". You have my permission to distribute the questionnaire to the providers who will attend the workshops conducted by Judy Blanding.

I wish you success on your project, and look forward to the reaults you find regarding the health training needs of child care providers.

Sincerely,

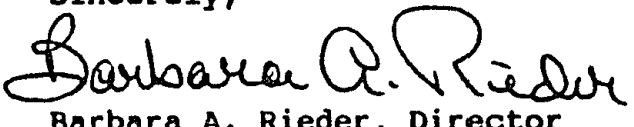

Barbara A. Rieder, Director

Public Health Nursing

$\mathrm{BAR} / \mathrm{mmr}$ 
Appendix E

Permission Letter from the Supervisor

of Neighborhood Day Care Program 


\section{California}

February 25, 1988

Anna Lu

41873 Higgins Way

Fremont, CA 94539

Dear Anna:

Please inform the Human Subjects Review Comittee at San Jose State University that the Neighborhood Day Care Program would be very pleased to participate in your study to "assess the health promotion behaviors and health training needs" of child care providers.

As part of our February Horkshop, the providers were told that our program had been asked to particlpate in a special study on child care and health. Each provider would receive a questionnaire to complete and return. Please send your questionnaire directly to the providers. I have enclosed a provider roster.

Thank you for thinking of us. He are looking forward to recelving the results of your study.

Sincerely,

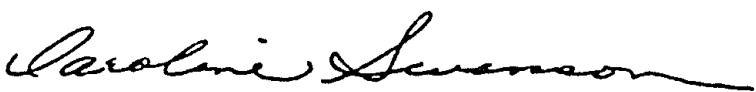

Caroline Swanson, P.H.N.

Supervisor, Neighborhood Day Care

CS:mm 
Appendix F

Approval Form from

Human Subjects Institutional Review Board

San Jose State University 
SAN JOSE STATE UHIVERSITY GRADUATE STUDIES AND RESEARCH

Human Subjects Institutional Review Board Project Proposal Review

1. the undersigned aber of the San Jose State University Huan. Subjects Institutional Review Board, have reviewed the following proposal subaitted to the Comenittee on MARHC 2. 1988 by:

Principal Investigator ANMA LU

Protocol 7277

Project Titie A STUDY TO ASSESS HEALTH-PROHOTION BEHAVIORS AND HEALTH-TRAIIIIIG MEEDS OF CHILD-CARE CENTER TEACHERS AND CHILO-CARE HOME PROVIDERS.

I recomend the following action (Indicate one):

1. Approved for ciearance as Involving ainial risk to thean Subjects

2. Approved for clearance with risk to Huan Subjects

3. Approved for clearance then the follouing conditions are aet:

4. Return to principal investigator for followiag reasons:

5. Expedited review (specify conditions(s) that merit expedited review): $\square$

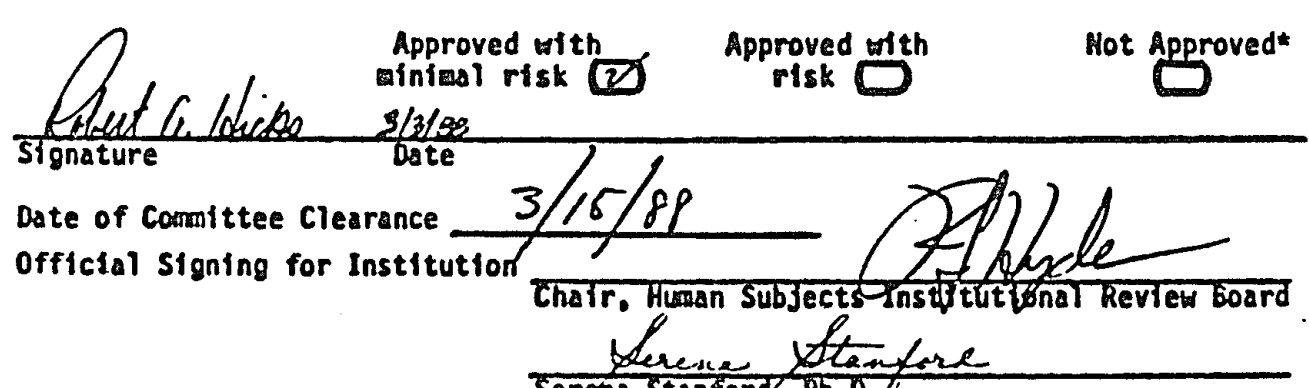

Sergna Stanford: Ph.0

Assoctate Acadenic Vice President for Graduate Studies and Research

San Jose Stete University Foundation

One Washington Square

San Jose, CA 95192-0139

(408) 924-1400

- Return to SJSUF for full hSIRB reviata: 